\title{
CT Imaging and Spontaneous Behavior Analysis After Osmotic Blood- Brain Barrier Opening in Wistar Rat
}

\author{
P. KOZLER ${ }^{1}$, V. RILJAK ${ }^{1}$, K. JANDOVÁ ${ }^{1}$, J. POKORNÝ ${ }^{1}$ \\ ${ }^{1}$ Institute of Physiology, First Faculty of Medicine, Charles University in Prague, Prague, Czech \\ Republic
}

Received March 15, 2014

Accepted July 10, 2014

\section{Summary}

In our previous experiments we demonstrated that osmotic opening of the blood brain barrier (BBB) in rats by administration of mannitol into the internal carotid artery leads to cerebral edema. The aim of this study was to confirm objectively the development of brain edema and determine whether it affects spontaneous locomotor activity in rats (SLA). Brain edema was verified by computer tomography (CT) examination of the brain and SLA was observed during open field test. Twenty four adult male rats were divided into four groups of six: (1) control animals (C), (2) controls with anesthesia (CA), (3) controls with sham surgery (CS), (4) experimental - osmotic opening of the BBB (MA). Osmotic BBB disruption manifested by reducing the density of brain tissue (hypodensity), suggesting a higher water content in the brain tissue. SLA was compared between C, CA, CS and MA groups and between MA and CA groups. Significant difference was found only between the control group and MA group. In the first $30 \mathrm{~min}$ of the examination, rats after the mannitol administration revealed a marked limitation of spontaneous locomotor activity. Experimental results demonstrated reduction of spontaneous locomotor activity in rats with induced brain edema.

\section{Key words}

Blood-brain barrier • Brain edema • Osmotic BBB disruption • CT - Open field test

\section{Corresponding author}

J. Pokorny, Institute of Physiology, First Faculty of Medicine, Charles University in Prague, Albertov 5, 12800 Prague 2, Czech Republic. E-mail: pokorny@lf1.cuni.cz

\section{Introduction}

Osmotic opening of the BBB (osmotic BBB disruption - oBBBD) was introduced into experimental practice by Rapoport in 1970 (Rapoport 1970). oBBBD was made available as a safe method for clinical practice thanks to Kroll and Neuwelt (Kroll and Neuwelt 1998). Currently oBBBD represents a part of the clinical protocols for the treatment of malignant brain tumors (Fortin et al. 2005, Bellavance 2008). The BBB opening is mediated partially by vasodilatation and partially by shrinkage of the endothelial cells. Both these factors finally resulted in widening of tight junction diameter (Kroll and Neuwelt 1998).

Our previous experimental findings show that the osmotic opening of the BBB allows penetration of high molecular weight substances into the brain (Kozler and Pokorny 2003), together with an increase of the cytoplasmic membrane permeability (Kozler and Pokorny 2004), leading to changes in myelin (Kozler et al. 2010) and mainly to an increase of the brain water content (Kozler et al. 2013). The brain status therefore fulfils criteria for brain oedema (Klatzo 1967, Kimelberg 1995).

While the principles and use oBBBD receives in literature adequate attention, objective evidence of the brain edema, together with description of behavioral changes in experimental animals after oBBBD has not yet been given. There are few data reporting certain EEG pattern changes after BBB integrity was disrupted. To our best knowledge $\mathrm{BBB}$ disruption and spontaneous behavior observation was not reported. Therefore, the aim of this study was to determine whether and how the spontaneous locomotor activity of rats is changed in relation to oBBBD. To prove brain edema induction after oBBBD, X-ray 
computed tomography examination (CT) of the brain was used.

\section{Material and Methods}

Twenty four naïve male Wistar albino rats were used in this experiment. The average weight of animal was 350-450 g (at the test day 1). All animals (breaded at the Institute of Physiology, 1st Faculty of Medicine, Charles University in Prague) were housed in standard $12 \mathrm{~h}$ light/dark cycles (with lights on at 06:00 h) in temperaturecontrolled environment $\left(22-23^{\circ} \mathrm{C}\right)$. All experiments took place between 08:00 and 15:00 in a room with lights on (light intensity between 150 and $200 \mathrm{~lx}$ at the level of cages). During the tests animals had no access to the food and water.

Animals were randomly divided into four experimental groups:

1. Controls - naïve animals received no treatment $(\mathrm{C})$

2. Animals treated with thiopental anesthesia only (CA)

3. Animals with thiopental anesthesia and arteria carotis interna (ACI) ligation (CS)

4. Animals with thiopental anesthesia, mannitol administration into ACI and its ligation, (MA)

\section{Microsurgical exposure of the internal carotid (ACI)}

Animals were put into the state of general anesthesia using intraperitoneal application of thiopental in the dose of $4 \mathrm{mg} / 100 \mathrm{~g}$ and allowed to ventilate spontaneously throughout the procedure. Starting from a skin incision along the midline between the upper end of the sternum and the mandible, the whole common carotid artery (ACC, arteria carotis communis) was exposed with a standard microsurgical technique and, beyond its bifurcation, also the proximal portions of the ACI and external carotid (ACE, arteria carotis externa), which was ligated close beyond the bifurcation. An intraluminal catheter was introduced into the ACC trunk from the arteriotomy for selective application of mannitol. With the application over and the catheter removed, the ACC was ligated distal to and proximal to the arteriotomy. The operation concluded with a single-layer suture (Kozler 2001).

\section{Osmotic opening of the $B B B$}

Mannitol 20\% (200 g in $1000 \mathrm{ml}$ of water for injection, $1098 \mathrm{mosmol} / \mathrm{l}$ ) in a dose of $5 \mathrm{ml} / \mathrm{kg}$ was selectively applied in the ACI at a rate of $0.12 \mathrm{ml} / \mathrm{sec}$ (Rapoport 2000). After the surgical intervention, animals were placed in boxes offering standard access to food and drink.

\section{Behavioral analysis}

After each treatment or surgical procedure animals were left undisturbed for $24 \mathrm{~h}$ and then were then placed and tested in Laboras apparatus (Metris B.V., Netherlands) to analyze their spontaneous behavior for one hour. Laboras ${ }^{\mathrm{TM}}$ is automated system for continuous behavior tracking and analysis. Mechanical vibrations generated by animal (locomotion, rearing etc.) are transformed into electrical signal. Such signals are processed, classified and compared with the predetermined characteristic patterns of Laboras software (Van de Weerd et al. 2001). During the monitoring sessions animals were left undisturbed. After the monitoring session, animals were returned to their home cages and housed for another seven days (food and water ad libitum). After that period all animals were placed in Laboras apparatus again and their behavioral pattern was observed during one hour period. All experiments were reviewed and approved by the Institutional Animal Care and Use Committee and are in agreement with the Czech Government Requirements and Requirements of European Communities Council Directive (86/609/EEC).

\section{CT examination}

In collaboration with the Institute of Physiology AV CR, for identification of brain edema Albira PET/CT system (Bruker, BioSpin, Spain) was used, voxel/pixel size of the CT scans was $29.16 \mathrm{~mm}$.

In three control rats $\mathrm{CT}$ scan of the brain was first obtained, then their BBB was opened with the described method and animals were again examined in CT. The second examination started at least $30 \mathrm{~min}$ after the mannitol injection.

Altogether six sets of CT pictures were obtained. To evaluate the brain density (Hounsfield units - HU) the coronar section $2.96 \mathrm{~mm}$ caudal to bregma, identified using multiplanar reconstruction, was used (Fig. 1). As a region of interest (Region of Interest - ROI) an area of 1.03 to $1.05 \mathrm{~cm}^{2}$ in all six tests was determined (Fig. 2). We compared the mean HU value (MV) at all six sections.

\section{Statistics}

Spontaneous behavior was analyzed and quantified in terms of locomotion activity (time spent by locomotion), rearing (time spent by rearing, vertical exploratory activity) and grooming (time spent by grooming, comfort behavior). 


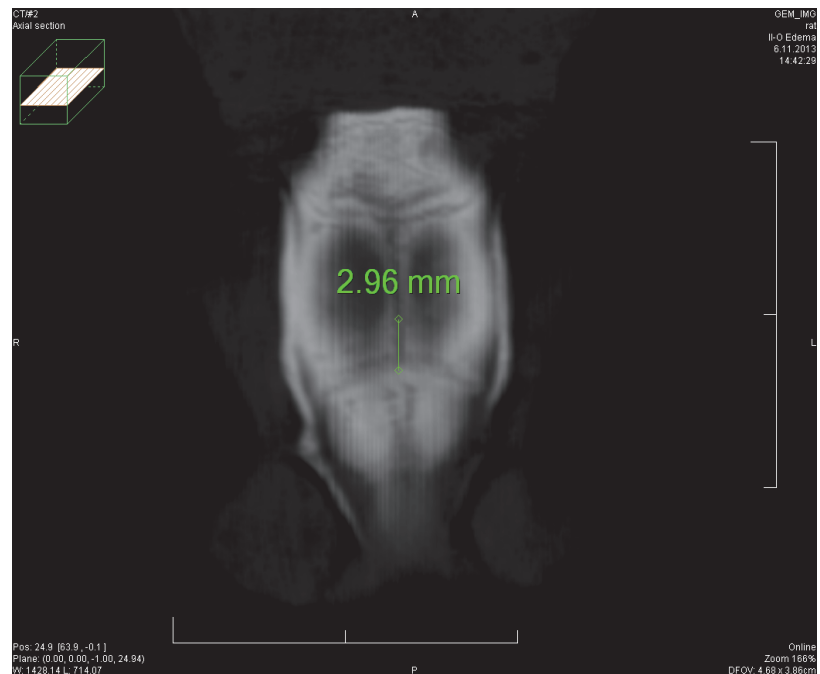

Fig. 1. Identification of the measured coronar section $(2.96 \mathrm{~mm}$ caudally from bregma).

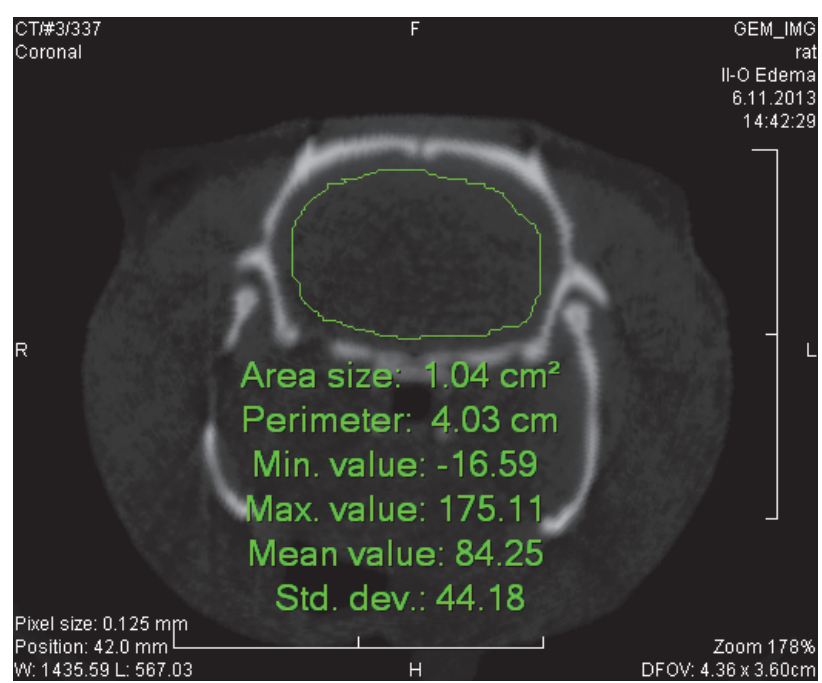

Fig. 2. Estimation of the region of interest (example).

Data from Laboras software were analyzed over ten minute intervals (0-10 $\mathrm{min}, 10-20 \mathrm{~min}, 20-30 \mathrm{~min}$, 30-40 min, 40-50 min, 50-60 min). Each measured behavioral parameter was analyzed separately. Laboras data were subjected to non-parametric tests (because of non-Gaussian data distribution). To compare the differences between particular groups within $10 \mathrm{~min}$ intervals Mann-Whitney test was used, if $\mathrm{p}<0.05$ results were considered as significant.

\section{Results}

\section{Open field test}

Behavioral data were analyzed in all experimental groups, results we always compared to data of naïve animals (C group). No significant difference was found in group CA (thiopental treatment) or group CS (ACI ligation) in time of locomotion, rearing or grooming. In group MA animals exhibited lower locomotor activity in the first half of session (30 $\mathrm{min})$, then they tended to habituate and their locomotor activity decreased to almost zero. The same pattern was observed in parameter "rearing" - decreased vertical activity was expressed during the first half of the session then the time spent by rearing was similar to controls. Grooming activity was lower in third analyzed interval, in remaining intervals experimental animals did not differ from controls. The results are summarized in the graph (Fig. 3).

\section{CT examination}

As the size and antero-posterior location of examined areas in all samples was identical, the measured data revealed difference in brain tissue density. After the $\mathrm{BBB}$ disruption (MA group), the brain density was more than $12 \mathrm{HU}$ (Hounsfield unit) smaller resp. lower in comparison with the basal values before the mannitol injection.

\section{Discussion}

CT examination revealed that in animals after the BBB disruption, the brain density was smaller than in the same animals at basal conditions. In all animals, the brain density value decreased by more than $12 \mathrm{HU}$. From a radiological point of view, such decrease in the brain density (hypodensity) indicates higher water content in brain tissue, which is a typical sign of brain edema (Clasen et al. 1981, Rose et al. 1989).

Dzialowski et al. (2004) showed that brain density at CT correlates with the water content in the brain. By the method of dry-wet weight and CT scan of the brain of rats after the middle cerebral artery occlusion they found a $1 \%$ increase in brain water content corresponding with the density decrease of $1.8 \mathrm{HU}$. Because we found in our previous work an increased water content in the brain of rats after the oBBBD by $1.1 \%$ (Kozler et al. 2013), and our present results show a hypodensity in oBBBD animals, it is possible to conclude that the $\mathrm{BBB}$ opening results in brain edema. At present it is possible to quantify precisely the $\mathrm{BBB}$ permeability using CT (Nguyen et al. 2013).

Study of the spontaneous locomotor activity of rats using open field test has a long history (Hall 1934, 
Walsh and Cummins 1976). At present, the measurement of horizontal locomotion, rearing and grooming activity are the most widely used methods of this field (Malkesman et al. 2013, Hamm 2001, Fujimoto et al. 2004, Crawley 2007). Malkesman and co-workers, in their extensive review, stated that in the field of traumatic brain injury, studies of the mental processes in experimental animals are still in the shadow of the very intensive and broad research of biological phenomena.

\section{MANNITOL/CONTROL}
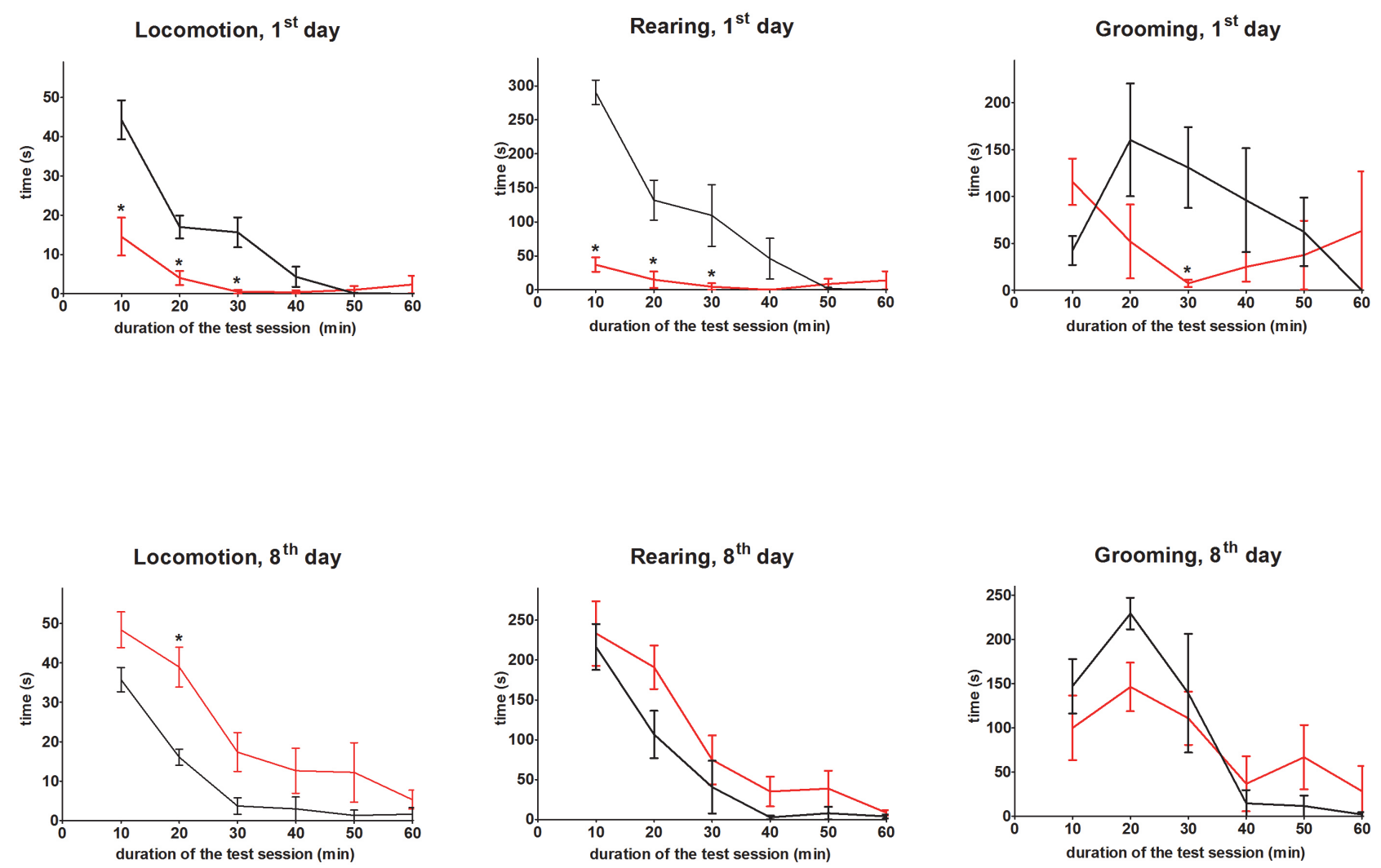

Fig. 3. Osmotic blood brain barrier opening affects the spontaneous behavior of rats. Upper graphs illustrate behavior $24 \mathrm{~h}$ after treatment (surgical procedure); the bottom graphs bring data from the recording one week after the treatment. Red lines bring data from mannitol treated animals; black lines represent controls (naïve controls). Differences significant at $p<0.05$ are marked with asterisk $(*)$, error bars were calculated as \pm SEM.

Similar situation is in the field of osmotic opening of the BBB. In the PubMed, only one paper dealing with the consequences oBBBD the behavior of rats was found. Yamaguchi et al. (1990) concluded that osmotic opening of the BBB does not affect the behavior of rats. Studied, however, was not the spontaneous locomotor activity, but the active avoidance learning.

Our results indicate that interventions like thiopental anesthesia, or sham operation (ACI ligation) does not influence the spontaneous locomotor activity compared to healthy rats. Only the rats $24 \mathrm{~h}$ after oBBBD clearly showed attenuation of the horizontal locomotion and rearing activity in the first $30 \mathrm{~min}$ and frequency grooming about the 30 th $\min (\mathrm{p}<0.05)$. This attenuation of behavioral activity was not present during the subsequent time of recording at the $1^{\text {st }}$ day and there was not expressed during the examination the 8th day after the mannitol administration. No such observations related to oBBBD can be found in the literature. Behavioral changes we observed cannot be explained only by BBB osmotic opening by mannitol. It is short, lasting up to $10 \mathrm{~min}$ and is fully reversible (Rapoport 2000, Kroll and Neuwelt 1998). We believe that the altered behavior was caused by impaired homeostatic mechanisms of the brain 
due to induced brain edema. If we consider that in addition to the increased water content in the brain also permeability of the $\mathrm{BBB}$ and cytoplasmic membranes is increased which may result in myelin impairment, the short-term and reversible depression of spontaneous locomotor activity of rats is understandable.

\section{Conflict of Interest}

There is no conflict of interest.

\section{Acknowledgements}

Supported with grant $\mathrm{P}-34 / \mathrm{LF} 1 / 7$

\section{References}

BELLAVANCE MA: Recent advances in blood-brain barrier disruption as a CNS delivery strategy. AAPS $J$ 10: 166$177,2008$.

CLASEN RA, HUCKMAN MS, VON ROENN KA, PANDOLFI S, LAING I, LOBICK JJ: A correlative study of computed tomography and histology in human and experimental vasogenic cerebral edema. J Comput Assist Tomogr 5: 313-327, 1981.

CRAWLEY JC: What's Wrong with My Mouse? 2nd ed. John Wiley \& Sons, Inc, Hoboken, New Jersey, 2007.

DZIALOWSKI I, WEBER J, DOERFLER A, FORSTING M, VON KUMMER R: Brain tissue water uptake after middle cerebral artery occlusion assessed with CT. J Neuroimaging 14: 42-48, 2004.

FORTIN D, DESJARDINS A, BENKO A, NIYONSEGA T, BOUDRIAS M: Enhanced chemotherapy delivery by intraarterial infusion and blood-brain barrier disruption in malignant brain tumors: the Sherbrooke experience. Cancer 103: 2606-2615, 2005.

FUJIMOTO ST, LONGHI L, SAATMAN KE, CONTE V, STOCCHETTI N, McINTOSH TK: Motor and cognitive function evaluation following experimental traumatic brain injury. Neurosci Biobehav Rev 28: 365-378, 2004.

HALL CS: Emotional behavior in the rat. I. Defecation and urination as measures of individual differences in emotionality. J Comp Physiol Psychol 18: 385-403, 1934.

HAMM RJ: Neurobehavioral assessment of outcome following traumatic brain injury in rats: an evaluation of selected measures. J Neurotrauma 18: 1207-1216, 2001.

KIMELBERG HK: Current concepts of brain edema - review of laboratory investigations. J Neurosurg 83: 1051-1059, 1995.

KLATZO I: Neuropathological aspects of brain edema. J Neuropathol Exp Neurol 26: 1-14, 1967.

KOZLER P: Osmotic opening of the blood-brain barrier in an experiment. (in Czech) Rozhl Chir 80: 393-396, 2001.

KOZLER P, POKORNÝ J: Altered blood-brain barrier permeability and its effect on the distribution of Evans blue and sodium fluorescein in the rat brain applied by intracarotid injection. Physiol Res 52: 607-614, 2003.

KOZLER P, POKORNÝ J: Effects of intracarotid injection of methylprednisolone on cellular oedema after osmotic opening of the blood-brain barrier in rats. Prague Med Rep 105: 279-290, 2004.

KOZLER P, RILJAK V, POKORNY J: Time-dependent axonal impairment in experimental model of brain oedema. Neuro Endocrinol Lett 31: 477-482, 2010.

KOZLER P, RILJAK V, POKORNÝ J: Both water intoxication and osmotic BBB disruption increase brain water content in rats. Physiol Res 62 (Suppl 1): S75-S80, 2013.

KROLL RA, NEUWELT EA: Outwitting the blood-brain barrier for therapeutic purposes: osmotic opening and other means. Neurosurgery 42: 1083-1100, 1998.

MALKESMAN O, TUCKER LB, OZL J, MCCABE JT: Traumatic brain injury - modeling neuropsychiatric symptoms in rodents. Front Neurol 4:157, 2013.

NGUYEN GT, COULTHARD A, WONG A, SHEIKH N, HENDERSON R, O'SULLIVAN JD, REUTENS DC: Measurement of blood-brain barrier permeability in acute ischemic stroke using standard first-pass perfusion CT data. Neuroimage Clin 22: 658-662, 2013.

RAPOPORT SI: Effect of concentrated solutions on blood-brain barrier. Am J Physiol 219: 270-274, 1970.

RAPOPORT SI: Osmotic opening of the blood-brain barrier: principles, mechanism, and therapeutic applications. Cell Moll Neurobiol 20: 217-230, 2000. 
RÓZSA L, GROTE EH, EGAN P: Traumatic brain swelling studied by computerized tomography and densitometry, Neurosurg Rev 12: 133-140, 1989.

VAN DE WEERD HA, BULTHUIS RJ, BERGMAN AF, SCHLINGMANN F, TOLBOOM J, VAN LOO PL, REMIE R, BAUMANS V, VAN ZUTPHEN LF: Validation of a new system for the automatic registration of behaviour in mice and rats. Behav Processes 53: 11-20, 2001.

WALSH RN, CUMMINS RA: The open-field test: a critical review. Psychol Bull 83: 482-504, 1976.

YAMAGUCHI M, NAGASHIMA T, KINOSHITA I, TSUKAMOTO Y: Opening of blood-brain barrier by infusion of hypertonic mannitol solution did not disturb the active avoidance learning of rats. Bulletin of Allied Medical Sciences - BAMS (Kobe) 6: 177-181, 1990. 